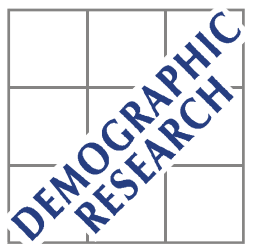

Demographic Research a free, expedited, online journal of peer-reviewed research and commentary in the population sciences published by the Max Planck Institute for Demographic Research Konrad-Zuse Str. 1, D-18057 Rostock · GERMANY www.demographic-research.org

DEMOGRAPHIC RESEARCH

VOLUME 10, ARTICLE 3, PAGES 61-82

PUBLISHED 12 MARCH 2004

www.demographic-research.org/Volumes/Vol10/3/

DOI: 10.4054/DemRes.2004.10.3

Descriptive Findings

\title{
Life Expectancy among LDS and Non-LDS in Utah
}

\author{
Ray M. Merrill
}

(C) 2004 Max-Planck-Gesellschaft. 


\section{Table of Contents}

1 Introduction $\quad 62$

2 Study Population $\quad 62$

3 Methods 63

$\begin{array}{lll}3.1 & \text { Data } & 63\end{array}$

3.2 Reliability of the Data 64

3.3 Record Linkage $\quad 64$

3.4 Affect of Tobacco Use on Life Expectancy 65

$\begin{array}{lll}4 & \text { Results } & 67\end{array}$

$\begin{array}{lll}5 & \text { Discussion } & 75\end{array}$

$\begin{array}{lll}6 & \text { Conclusion } & 78\end{array}$

$\begin{array}{ll}\text { References } & 79\end{array}$ 
Descriptive Findings

\title{
Life Expectancy among LDS and Non-LDS in Utah
}

\author{
Ray M. Merrill ${ }^{1}$
}

\begin{abstract}
This paper compares life expectancy between members of the Church of Jesus Christ of Latter-day Saints (LDS or Mormons) and non-LDS in Utah. It examines the extent to which tobacco-related deaths explain variation in life expectancy between LDS and non-LDS.

Complete life table estimates were derived using conventional methods and crosssectional data for white males and females from 1994-1998. Life expectancy was 77.3 for LDS males, 70.0 for non-LDS males, 82.2 for LDS females, and 76.4 for non-LDS females. For those alive at age 80, the remaining years of life expected were 8.2 for LDS males, 6.5 for non-LDS males, 10.3 for LDS females, and 7.1 for non-LDS females. Years of life expected increased more so among non-LDS after we removed deaths associated with tobacco use from the life table.

A comparison between LDS and non-LDS of the adjusted life expectancy estimates indicates that although differential tobacco use explains some of the higher life expectancy in LDS, it only accounts for about 1.5 years of the 7.3 year difference for males and 1.2 years of the 5.8 year difference for females. Higher life expectancy experienced among LDS not explained by tobacco-related deaths may be due to factors associated with religious activity in general, such as better physical health, better social support, and healthier lifestyle behaviors. Religious activity may also have an independent protective effect against mortality.
\end{abstract}

$1 \mathrm{PhD}, \mathrm{MPH}$, Department of Health Science, College of Health and Human Performance; Brigham

Young University; 213 Richards Building, Provo, Utah 84602. USA.

E-mail: Ray_Merrill@byu.edu. Telephone: 801-422-9788, Facsimile: 801-422-0273. 


\section{Introduction}

Life expectancy is a useful index measure for comparing health status within groups over time and between groups at points in time (Sen 1987). Improvements in our understanding of disease risk factors, improvements in technology and economic development, and the dissemination of risk factor knowledge and economic resources have dramatically increased life expectancy in the past several decades among many populations throughout the world (Morbidity and Mortality Weekly Report 2003; Michaud, Murray, and Bloom 2001). Tobacco use is among those behaviors that has slowed the increasing life expectancy (Murray and Lopez 1997a; Peto et al. 1996; Stinson et al. 1996). A number of diseases and conditions associated with tobacco use have been identified in epidemiologic studies (Single et al. 2000; Single et al. 1999). The extent that these diseases and conditions have slowed the increasing life expectancy is unclear.

This paper compares life expectancy between members of the Church of Jesus Christ of Latter-day Saints (LDS or Mormons) and non-LDS in Utah. Comparatively high life expectancy among LDS males has been previously observed, based on data from California and Utah during 1968-1975 (Enstrom 1978). The author of this earlier study attributed some of the higher life expectancy among LDS to their lower levels of tobacco use. The LDS population has historically experienced low tobacco use (Merrill, Lindsay, and Lyon 1999; Alexander 1981), and, in Utah, currently reflects a population meeting the Healthy People 2010 objectives related to tobacco (U.S. Division of Health and Human Services 2000). The study by Enstrom (1978) was limited to males and the influence of tobacco use on life expectancy was not quantified. The current study derives life expectancy for LDS and non-LDS males and females and considers the extent that differences in life expectancy between LDS and non-LDS males and females are explained by tobacco-related deaths.

\section{Study Population}

The LDS Church is among those religions that provide strong directives for personal living, including health behaviors, which have resulted in a distinctive life style. Low tobacco smoking among LDS compared with non-LDS is well documented (Merrill, Hilton, and Daniels 2003; Merrill and Thygerson 2001; Merrill, Lindsay, and Lyon 1999; West, Lyon, and Gardner 1980), and stems from about 1920 when abstention from tobacco use became required of members of the Church for priesthood ordination and advancement, missionary service, leadership positions in the Church, and admittance to the temple (Alexander 1981). It should be noted that while only devout 
members are allowed to enter LDS temples, buildings used for weekly meetings of worship are open to all people. Today, less than $1 \%$ of member of the LDS Church who attend church weekly smoke cigarettes (Merrill 2002; Merrill and Thygerson 2001).

Utah currently has the highest percentage of Christian church adherents (U.S. Census Bureau 2000a) and the highest percentage affiliated with a single religion in the nation (Kosmin and Lachman 1993). About $70 \%$ of the 2.3 million population in the state is affiliated with the LDS Church (Merrill and Thygerson 2001; U.S. Census Bureau 2001). Current tobacco smoking in Utah is approximately 6.5\% (9.2\% in males and $4.1 \%$ in women) for LDS and $23.7 \%$ (24.5\% in males and $23.1 \%$ in women) for non-LDS (Merrill and Thygerson 2001). The percentage of non-LDS who currently smoke is about the same as that found nationally, 23.2\% (Nationwide Tobacco Use 2001).

\section{Methods}

\subsection{Data}

Complete life table estimates were derived using conventional life table methods (Selvin 1996). The life tables were based on current cross-sectional mortality rates for the time period 1994 through 1998. Mortality rates for LDS and non-LDS white males and females were determined from death records from the Utah Department of Health, deceased membership records from the LDS Church, state population estimates from the United States Bureau of the Census, and state LDS population estimates from the LDS Church. The state death records include name, gender, date of birth, date of death, marital status, race, county of death, and cause of death with classification codes from the International Classification of Diseases, $9^{\text {th }}$ Revision (ICD-9-CM 1989). In order to classify individuals as LDS or non-LDS, state death records were linked with LDS Church deceased membership records. Denominators used to compute death rates for LDS were based on LDS population estimates from the LDS Church membership records. Non-LDS denominators were calculated by taking the difference between state population estimates from the US Bureau of the Census and the LDS Church's population estimates from membership records. 


\subsection{Reliability of the Data}

Since 1967, Utah has had a medical examiner system where unnatural and/or unattended deaths are investigated, and the medical examiner completes the death certificate indicating the cause of death. The attending physician identifies other causes of death. Accurate identification of the cause of death is based on the judgment and expertise of the individual completing the death certificate.

The U.S. Bureau of the Census provides state level population estimates. The methodology used for obtaining these estimates is described elsewhere (U.S. Census Bureau 2000b). Some variability is associated with these estimates, yet no estimates of sampling error are provided.

The LDS Church's record keeping system and the accuracy of their records has been described previously (Enstrom 1975). When a child is born into a family of the LDS religion, a church membership record is made. Membership records are also generated for converts to the church. Church records are created at the congregation level (typically consisting of a group of 100 to 400 members) and then forwarded to the general church headquarters in Salt Lake City, Utah, where the individual record is added to the general membership database. These records include name, date of birth, parents' names, marital status, name of spouse, date of church ordinances, and current address. Each congregation has a lay membership clerk who is responsible for creating and updating records for the individuals in that congregation. When a member dies, the clerk reports the death to the LDS Church Member and Statistical Records Division, where the record is updated and archived in the Church's deceased membership file.

\subsection{Record Linkage}

State death records were linked to LDS deceased membership records by the probabilistic linking program LinkPro (Wajda et al. 1991). Probabilities were calculated to identify whether a pair of records refers to the same person. Eleven identifying characteristics common to both data sets were used, including last name, first name, middle name, birth day, birth month, birth year, marital status, county of death, and SOUNDEX versions of the three names. A SOUNDEX version of a name is a numerical value for that name; its purpose is to account for different spellings of the same name. Records were required to match on at least seven of the 11 variables. This number has been sufficient in previous linkage projects conducted by the author. A relatively few number of ambiguous matches were hand-checked.

There were 30,819 male deaths and 28,080 female deaths reported to the Utah

Department of Health in 1994-1998. Using Linkpro, 17,427 of 18,005 (96.7\%) LDS 
male deceased membership records and 17,234 of 17,859 (96.5\%) LDS female deceased membership records matched a state death record. State death records that failed to link to LDS deceased membership records were initially classified as nonLDS. To determine whether any non-LDS were misclassified, the name and birth date of each individual in the unlinked file was sent to the LDS Membership and Records Department where this information was compared with the Church's complete membership database, which includes both living and deceased membership records. Non-LDS state death records that matched church records on complete birth date and first and last names were reviewed by hand to verify whether or not they were an actual match. Of the 24,238 unlinked records that were initially classified as non-LDS, 4,215 (17.4\%) were matched to a church record in this manner. Of the deaths reported to the Utah Department of Health in 1994-1998, 19,657 (63.8\%) males were classified as LDS and $19,219(68.4 \%)$ females were classified as LDS.

\subsection{Affect of Tobacco Use on Life Expectancy}

To determine how lifetime and age-conditional life expectancy would improve among the LDS and non-LDS populations in the absence of tobacco-related deaths:

1. Age-specific numbers of tobacco-related deaths were derived for LDS;

2. Tobacco-related deaths were subtracted from the overall number of deaths for LDS within each age group; and

3. These new death counts were applied to the life table.

These steps were repeated for non-LDS. To estimate age-specific numbers of tobacco-related deaths, causes of death associated with tobacco use were first identified. Then, the proportion of deaths associated with tobacco was determined.

Deaths associated with tobacco use have been summarized from review articles and meta-analyses (Single et al. 2000; Single et al. 1999). Death counts for each of these diseases and conditions were derived separately for LDS and non-LDS in the years 1994 through 1998. The etiologic fraction indicating the proportion of death associated with tobacco use was derived from the following formula: $\left[\mathrm{P}_{1}\left(\mathrm{RR}_{1}-1\right)+\right.$ $\left.\mathrm{P}_{2}\left(\mathrm{RR}_{2}-1\right)\right] /\left[1+\mathrm{P}_{1}\left(\mathrm{RR}_{1}-1\right)+\mathrm{P}_{2}\left(\mathrm{RR}_{2}-1\right)\right]$, where $\mathrm{P}_{1}$ and $\mathrm{P}_{2}$ are the prevalence of former and current smoking and $R_{1}$ and $R_{2}$ are the relative risk estimates of death associated with former and current smoking, respectively. Estimates of the number of deaths attributable to tobacco use were obtained by calculating the etiologic fractions from relative risks and smoking prevalence data, and then applying the etiologic fractions to 
the number of deaths in the state for each cause of death by age, gender, and LDS status.

Relative risks were taken from Single et al. (2000), personal correspondence with Dr. Single, and for the condition "heart failure ill-defined," from the 1989 Surgeon General Report (U.S. Division of Health and Human Services 1989). The relative risks were obtained from pooled estimates of relative risk rather than from single studies, except in the case of "heart disease ill-defined," and reflect several recent studies, numerous tobacco-related diseases, and a wide range of ages. We assume the relative risk measures from these other studies are representative of the Utah population.

Smoking prevalence was estimated from the 1996 Utah Health Status Survey (Table 1). We could not determine from our data whether duration of smoking was similar between LDS and non-LDS smokers. However, no difference was observed between LDS and non-LDS, for either males (chi-square $\mathrm{p}=0.5509$ ) or females (chisquare $\mathrm{p}=0.2724$ ), in the average number of cigarettes smoked per day among current smokers, based on the 1996 Utah Health Status Survey.

Table 1: $\quad$ Prevalence of tobacco use for white males and females 18 years of age and older according to LDS status in Utah

\begin{tabular}{lrrrrrr}
\hline & \multicolumn{2}{c}{ LDS } & \multicolumn{2}{c}{ Non-LDS } & \multicolumn{2}{c}{ Total } \\
Smoking Status & Men & Women & Men & Women & Men & Women \\
\hline Former & $16.5 \%$ & $7.5 \%$ & $28.5 \%$ & $22.0 \%$ & $20.6 \%$ & $13.9 \%$ \\
Current & $9.2 \%$ & $4.2 \%$ & $25.4 \%$ & $23.2 \%$ & $11.4 \%$ & $9.3 \%$ \\
\hline
\end{tabular}

Data source: Utah Health Status Survey, 1996. Cigarette smoking status was self-declared by survey respondents, June-August of 1996. 


\section{Results}

Estimated numbers of death associated with tobacco use are presented for LDS and non-LDS white males and females in Table 2. Percentages corresponding to each of the listed causes of death attributed to tobacco vary considerably. Mortality rates per 100,000 for deaths attributed to tobacco were 33.9 for LDS males, 133.1 for non-LDS males, 18.1 for LDS females, and 89.0 for non-LDS females.

Estimated expected number of years of life remaining after age $x$ are presented for LDS and non-LDS white males (Figure 1) and females (Figure 2). Number of years of life remaining after age $x$ are consistently higher for LDS compared with non-LDS across the age span. Survival curves from the life tables for LDS and non-LDS white males (Figure 3) and females (Figure 4) are also presented. The percentage alive at age $x$ remains higher for LDS compared with non-LDS at each age. Adjusted life expectancy and survival curves are also calculated and presented in these figures for LDS and non-LDS populations, based on total deaths subtracted by tobacco-related deaths. 
Demographic Research - Volume 10, Article 3

Table 2: $\quad$ Mortality associated with tobacco use among white males and females from 1994 through 1998 by ICD-9 codes (Males)

\begin{tabular}{|c|c|c|c|c|c|}
\hline Cause & ICD-9 Code(s) & Total & $\begin{array}{c}\text { Expected } \\
\text { Attributed } \\
\text { to Tobacco }\end{array}$ & Total & $\begin{array}{c}\text { Expected } \\
\text { Attributed } \\
\text { to Tobacco } \\
\end{array}$ \\
\hline & & \multicolumn{2}{|c|}{ LDS Males } & \multicolumn{2}{|c|}{ Non-LDS Males } \\
\hline $\begin{array}{l}\text { Lip and oropharyngeal } \\
\text { cancer }\end{array}$ & $\begin{array}{l}140-141,143-146 \\
148-149,230.0\end{array}$ & 28 & $9.4(33.6 \%)$ & 30 & $16(53.3 \%)$ \\
\hline Oesophageal cancer & $150,230.1$ & 96 & $15(15.6 \%)$ & 52 & $26(50.0 \%)$ \\
\hline Laryngeal cancer & $161,231.0$ & 19 & $9(47.4 \%)$ & 19 & $13(68.4 \%)$ \\
\hline Heart failure, ill defined & $428-429$ & 921 & $48(5.2 \%)$ & 414 & $97(23.4 \%)$ \\
\hline Stroke & $430-438$ & 1180 & 99 (8.4\%) & 471 & $99(21.0 \%)$ \\
\hline Stomach cancer & $151,230.2$ & 100 & $2.4(2.4 \%)$ & 45 & $5.4(12.0 \%)$ \\
\hline Anal cancer & $\begin{array}{l}154.2-154.3,230.5- \\
230.6\end{array}$ & 2 & $0(12.7 \%)$ & 1 & $0.4(40.0 \%)$ \\
\hline Pancreatic cancer & $157,230.9$ & 211 & $7.2(3.4 \%)$ & 76 & $16(21.1 \%)$ \\
\hline Lung cancer & $162,231.2$ & 584 & $393(67.3 \%)$ & 554 & 457 (82.5\%) \\
\hline Penile cancer & 187.1-187.4 & 5 & $0.3(6.0 \%)$ & 2 & $0.5(25.0 \%)$ \\
\hline Bladder cancer & $188,233.7$ & 108 & 15 (13.9\%) & 69 & 27 (39.1\%) \\
\hline Renal cancer & 189.0-189.2 & 3 & $0.3(10.0 \%)$ & 2 & $.5(25.0 \%)$ \\
\hline Tobacco abuse & 305.1 & 1 & $1(100.0 \%)$ & 1 & $1(100.0 \%)$ \\
\hline Cardiac dysrhythmias & 427 & 282 & $10(3.5 \%)$ & 107 & $21(19.6 \%)$ \\
\hline Ischemic heart disease & $410-414$ & 3397 & $156(4.6 \%)$ & 1514 & 317 (20.9\%) \\
\hline $\begin{array}{l}\text { Pulmonary circulatory } \\
\text { disease }\end{array}$ & $415.0,416-417$ & 43 & $8.3(19.3 \%)$ & 13 & $10(76.9 \%)$ \\
\hline Arterial disease & $440-448$ & 359 & $40(11.1 \%)$ & 183 & $70(38.3 \%)$ \\
\hline $\begin{array}{l}\text { Pneumonia and } \\
\text { influenza }\end{array}$ & $480-487$ & 757 & $30(4.0 \%)$ & 356 & $60(16.9 \%)$ \\
\hline $\begin{array}{l}\text { Chronic obstructive } \\
\text { pulmonary disease }\end{array}$ & $490-492,496$ & 794 & $331(41.7 \%)$ & 520 & $413(79.4 \%)$ \\
\hline Ulcers & $531-534$ & 107 & $26(24.3 \%)$ & 112 & $43(38.4 \%)$ \\
\hline Chron's disease & 555 & 7 & $1.7(24.3 \%)$ & 9 & $3.0(33.3 \%)$ \\
\hline Ulcerative colitis & 556 & 43 & $1.0(2.3 \%)$ & 13 & $1.3(10.0 \%)$ \\
\hline Stillbirth & $740-759,760-779$ & 187 & $6.5(3.5 \%)$ & 269 & $17(6.3 \%)$ \\
\hline $\begin{array}{l}\text { Sudden infant death } \\
\text { syndrome }\end{array}$ & 798.0 & 36 & $6.6(18.3 \%)$ & 47 & $15(31.9 \%)$ \\
\hline $\begin{array}{l}\text { Accidents by fire and } \\
\text { flames }\end{array}$ & E890-E899 & 21 & $5.8(27.6 \%)$ & 25 & $5.8(23.2 \%)$ \\
\hline
\end{tabular}


Table 2 (cont.): Mortality associated with tobacco use among white males and females from 1994 through 1998 ICD-9 codes (Females)

\begin{tabular}{|c|c|c|c|c|c|}
\hline Cause & ICD-9 Code(s) & Total & $\begin{array}{l}\text { Expected } \\
\text { Attributed } \\
\text { to Tobacco }\end{array}$ & Total & $\begin{array}{l}\text { Expected } \\
\text { Attributed } \\
\text { to Tobacco }\end{array}$ \\
\hline & & \multicolumn{2}{|c|}{ LDS Females } & \multicolumn{2}{|c|}{ Non-LDS Females } \\
\hline $\begin{array}{l}\text { Lip and oropharyngeal } \\
\text { cancer }\end{array}$ & $\begin{array}{l}140-141,143-146 \\
148-149,230.0\end{array}$ & 17 & $2.9(17.1 \%)$ & 16 & $8(50.0 \%)$ \\
\hline Oesophageal cancer & $150,230.1$ & 21 & $3.3(4.0 \%)$ & 13 & $6.1(46.9 \%)$ \\
\hline Laryngeal cancer & $161,231.0$ & 1 & $.3(30.0 \%)$ & 3 & $2(66.7 \%)$ \\
\hline Heart failure, ill defined & $428-429$ & 1228 & $49(4.0 \%)$ & 412 & $67(16.3 \%)$ \\
\hline Stroke & $430-438$ & 1798 & $73(4.1 \%)$ & 669 & $118(17.6 \%)$ \\
\hline Stomach cancer & $151,230.2$ & 71 & $1.8(2.5 \%)$ & 29 & $3.1(10.7 \%)$ \\
\hline Anal cancer & $\begin{array}{l}154.2-154.3,230.5- \\
230.6\end{array}$ & 2 & $1.8(2.5 \%)$ & 2 & $0.8(40.0 \%)$ \\
\hline Pancreatic cancer & $157,230.9$ & 170 & $7.7(4.5 \%)$ & 83 & $16(19.3 \%)$ \\
\hline Lung cancer & $162,231.2$ & 329 & $141(42.9 \%)$ & 348 & 267 (76.7\%) \\
\hline Cervical Cancer & $180,233.1$ & 50 & $2.6(5.2 \%)$ & 33 & $6.4(19.4 \%)$ \\
\hline Vulvar cancer & 184.4 & 7 & $0.8(11.4 \%)$ & 4 & $1.6(40.0 \%)$ \\
\hline Bladder cancer & $188,233.7$ & 44 & $4.8(10.9 \%)$ & 21 & $7.4(35.2 \%)$ \\
\hline Renal cancer & 189.0-189.2 & 0 & $0(0.0 \%)$ & 3 & $0.7(23.3 \$)$ \\
\hline Tobacco abuse & 305.1 & 2 & $2(100.0 \%)$ & 2 & $2(100.0 \%)$ \\
\hline Cardiac dysrhythmias & 427 & 387 & 15 (3.9\%) & 134 & $22(16.4 \%)$ \\
\hline Ischemic heart disease & $410-414$ & 2752 & $45(1.6 \%)$ & 958 & $147(15.3 \%)$ \\
\hline $\begin{array}{l}\text { Pulmonary circulatory } \\
\text { disease }\end{array}$ & $415.0,416-417$ & 54 & 24 (44.4\%) & 14 & $11(78.6 \%)$ \\
\hline Arterial disease & $440-448$ & 309 & $35(11.3 \%)$ & 144 & $50(34.7 \%)$ \\
\hline $\begin{array}{l}\text { Pneumonia and } \\
\text { influenza }\end{array}$ & $480-487$ & 977 & $39(4.0 \%)$ & 384 & $57(14.8 \%)$ \\
\hline $\begin{array}{l}\text { Chronic obstructive } \\
\text { pulmonary disease }\end{array}$ & $490-492,496$ & 431 & $192(44.5 \%)$ & 387 & 297 (76.7\%) \\
\hline Ulcers & $531-534$ & 100 & $12(12.0 \%)$ & 88 & $30(34.1 \%)$ \\
\hline Chron's disease & 555 & 13 & $1.6(12.3 \%)$ & 10 & $4(40.0 \%)$ \\
\hline Ulcerative colitis & 556 & 54 & $2(3.7 \%)$ & 14 & $0.9(6.4 \%)$ \\
\hline Stillbirth & $740-759,760-779$ & 128 & $1.4(1.1 \%)$ & 202 & $12(5.9 \%)$ \\
\hline $\begin{array}{l}\text { Sudden infant death } \\
\text { syndrome }\end{array}$ & 798.0 & 23 & $1.6(7.0 \%)$ & 30 & $8.7(29.0 \%)$ \\
\hline $\begin{array}{l}\text { Accidents by fire and } \\
\text { flames }\end{array}$ & E890-E899 & 10 & $2.3(23.0 \%)$ & 9 & $2.1(23.3 \%)$ \\
\hline
\end{tabular}


Demographic Research - Volume 10, Article 3

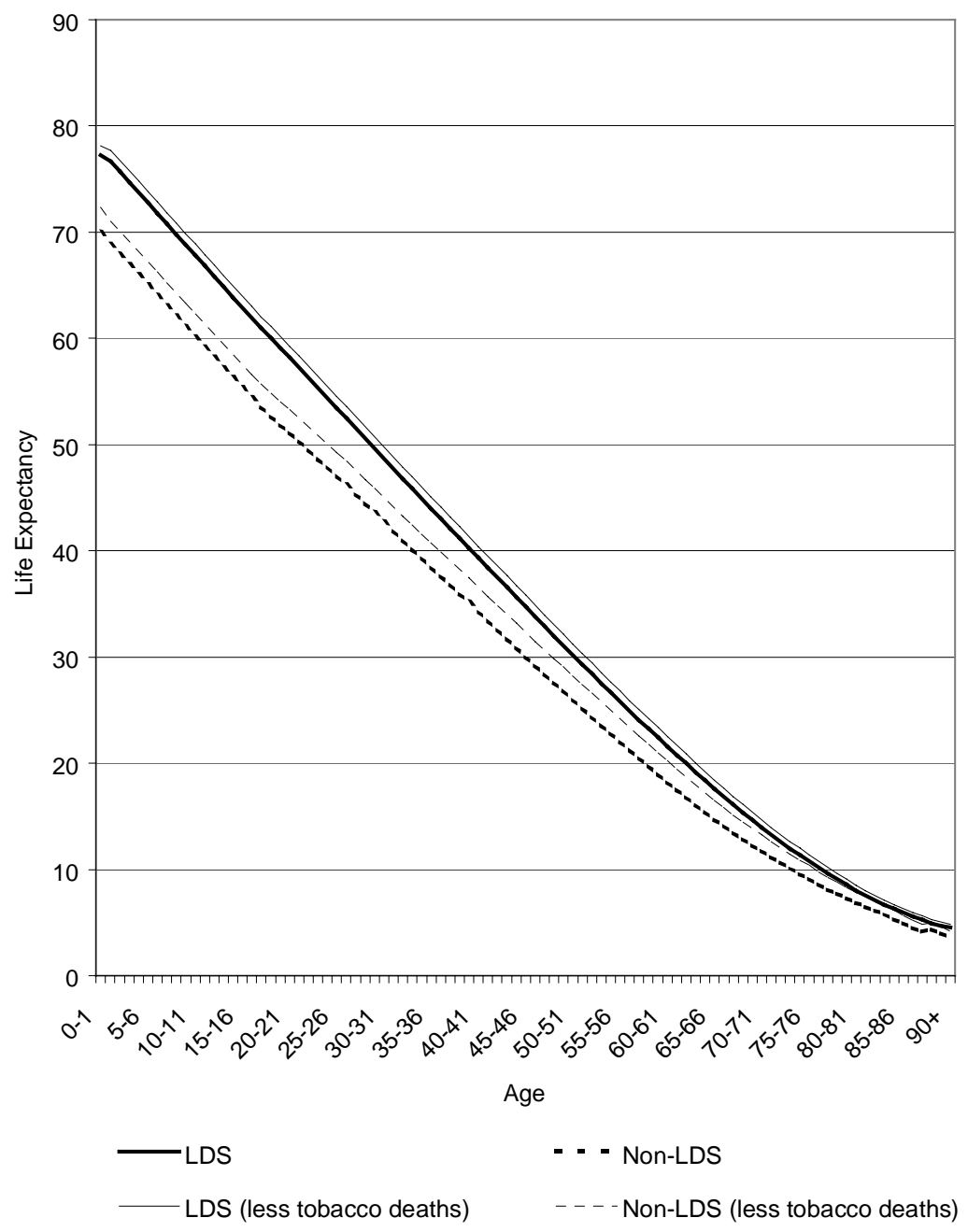

Figure 1: $\quad$ Expected number of years of life remaining after age $x$ for white LDS and non-LDS males, with hypothetical curves for LDS and non-LDS assuming no tobacco-related deaths 
Demographic Research - Volume 10, Article 3

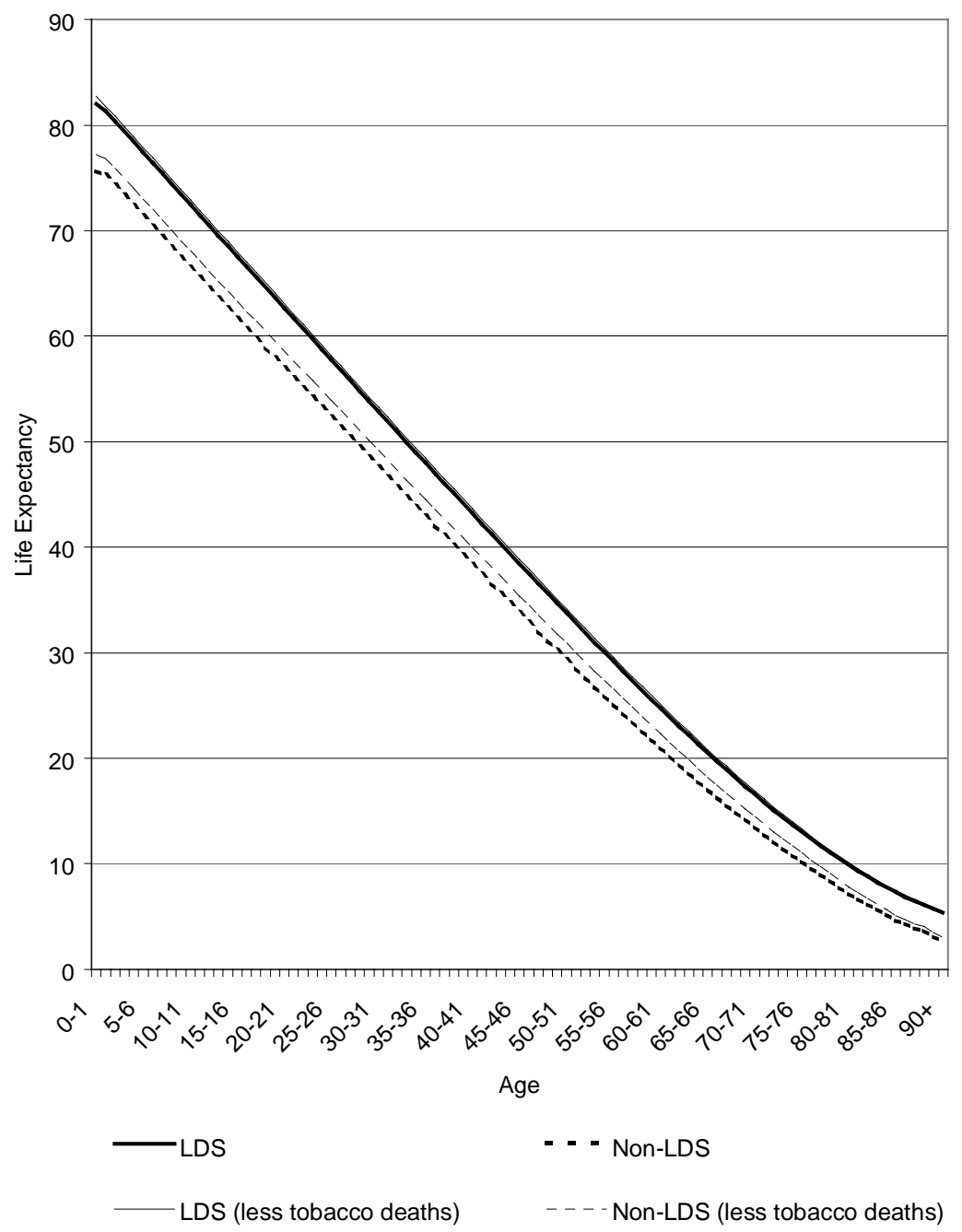

Figure 2: $\quad$ Expected number of years of life remaining after age $x$ for white LDS and non-LDS females, with hypothetical curves for LDS and non-LDS assuming no tobacco-related deaths 


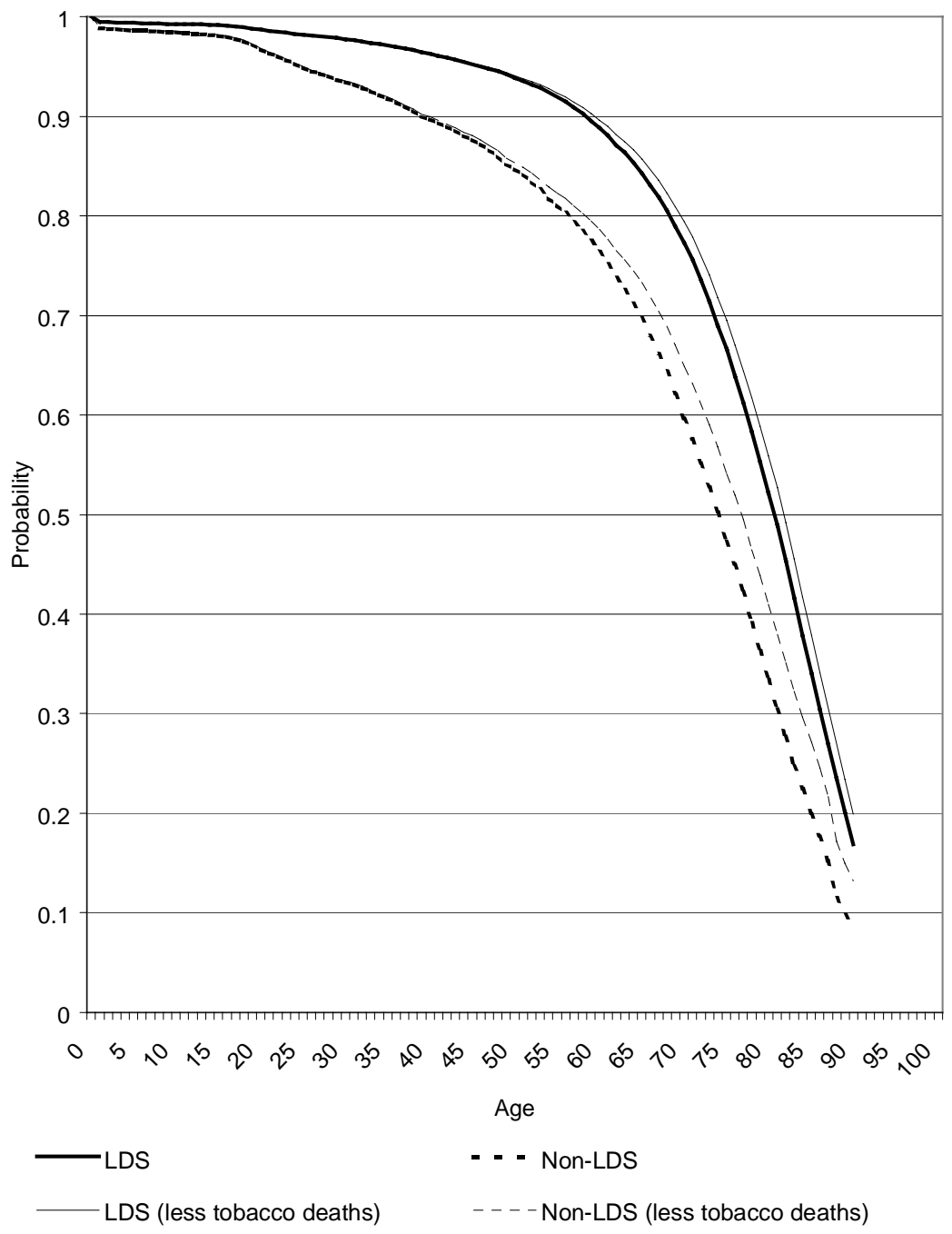

Figure 3: $\quad$ Survival curve from the life table for LDS and non-LDS males, with hypothetical curves for LDS and non-LDS assuming no tobacco-related deaths 
Demographic Research - Volume 10, Article 3

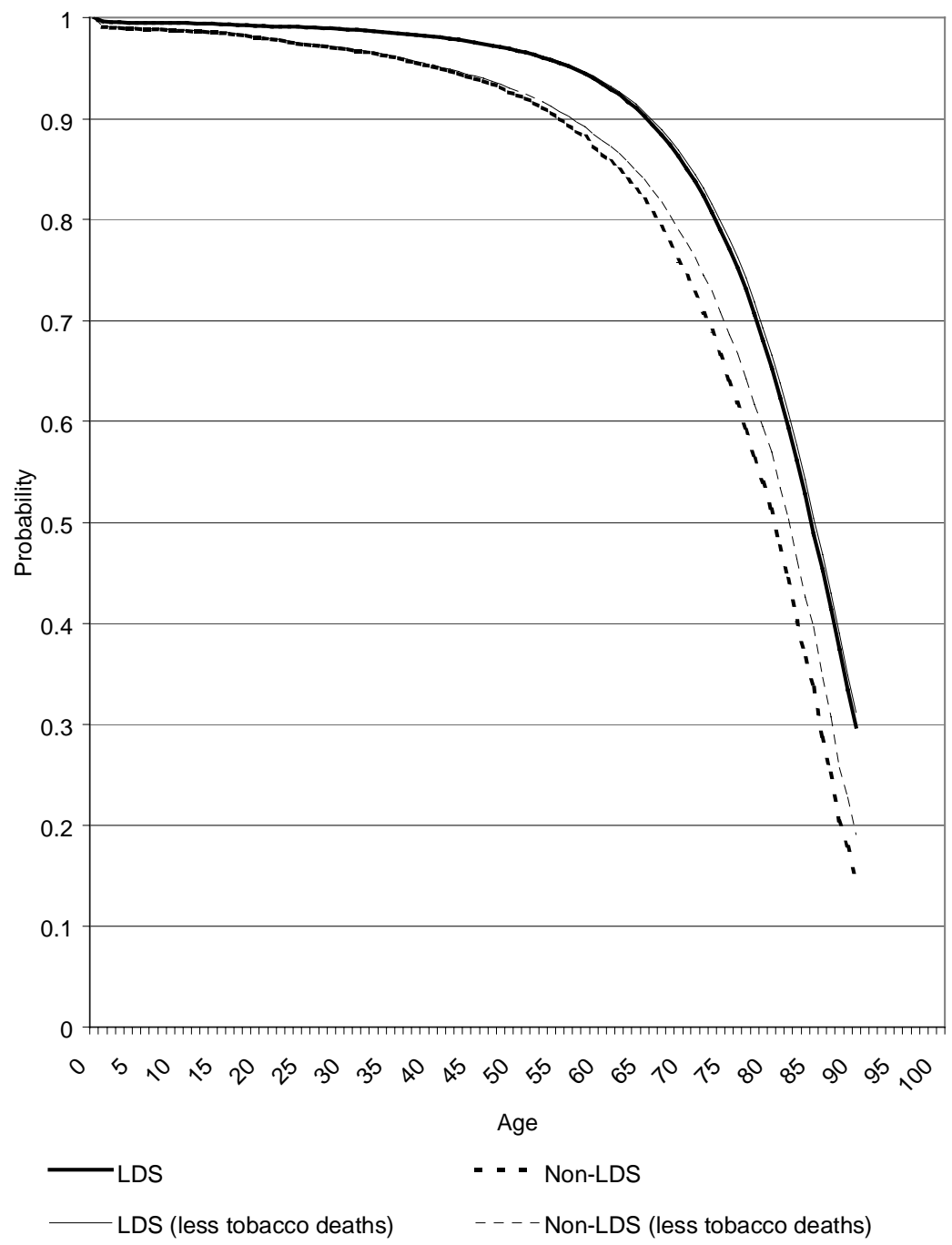

Figure 4: $\quad$ Survival curve from the life table for LDS and non-LDS females, with hypothetical curves for LDS and non-LDS assuming no tobacco-related deaths 
Another way to look at this data is to present the percentage of deaths attributed to tobacco use for white males and females according to LDS status. Because of long latency periods often associated with tobacco-related diseases, deaths attributed to tobacco have their primary impact in later life. By ages 85 years and older, tobaccorelated deaths explain the following percentages of all deaths: $4.0 \%$ for LDS males, $16.0 \%$ for non-LDS males, $2.6 \%$ for LDS females, and $11.5 \%$ for non-LDS females.

Estimated years of life expected for individuals alive at selected ages are presented for LDS and non-LDS males and females in Table 3. The additional number of years of life experienced by LDS compared with non-LDS was 7.3 for white males and 5.8 for white females. Additional years of life among LDS decreased as we conditioned on successively older ages. Nevertheless, even among those alive at age 80, LDS experienced more years of life than non-LDS, 1.7 for white males and 3.2 for white females. Estimated years of life expected increased after adjustment was made for tobacco-related deaths, more so among non-LDS. However, a comparison between estimates of adjusted life expectancy for LDS and non-LDS indicates that although differential tobacco use explains some of the higher life expectancy in LDS, it only accounts for about 1.5 years of the 7.3 year difference for males and 1.2 years of the 5.8 year difference for females.

Table 3: $\quad$ Years of life expected for white males and females alive at age $\mathrm{x}$, according to LDS status

\begin{tabular}{lcccccc}
\hline Age $x$ & $\begin{array}{c}\text { LDS } \\
\text { Males }\end{array}$ & $\begin{array}{c}\text { Non-LDS } \\
\text { Males }\end{array}$ & Difference & $\begin{array}{c}\text { LDS } \\
\text { Females }\end{array}$ & $\begin{array}{c}\text { Non-LDS } \\
\text { Females }\end{array}$ & Difference \\
\hline Unadjusted & & & & & & \\
0 & 77.3 & 70.0 & 7.3 & 82.2 & 76.4 & 5.8 \\
20 & 58.2 & 51.8 & 6.4 & 62.9 & 57.6 & 5.3 \\
40 & 39.4 & 34.3 & 5.1 & 43.4 & 38.6 & 4.8 \\
60 & 21.6 & 17.9 & 3.7 & 25.0 & 21.1 & 3.9 \\
80 & 8.2 & 6.5 & 1.7 & 10.3 & 7.1 & 3.2 \\
\hline Adjusted (less tobacco deaths) & & & & & \\
0 & 78.1 & 72.3 & 5.8 & 82.7 & 78.1 & 4.6 \\
20 & 59.0 & 54.0 & 5.0 & 63.3 & 59.2 & 4.1 \\
40 & 40.2 & 36.6 & 3.6 & 43.9 & 40.3 & 3.6 \\
60 & 22.3 & 19.9 & 2.4 & 25.4 & 22.4 & 3.0 \\
80 & 8.5 & 7.5 & 1.0 & 10.5 & 7.7 & 2.8 \\
\hline
\end{tabular}


The percentage of those alive at selected ages for LDS and non-LDS males and females, based on the life table, are presented in Table 4. At age 50, the addition in percentage of life remaining for LDS compared with non-LDS was $6.7 \%$ for white males and $3.2 \%$ for white females. The gap between LDS and non-LDS increased from age 50 to age 80 from $6.7 \%$ to $18.4 \%$ for white males, and from $3.2 \%$ to $12.4 \%$ for white females. At age 80, the percentage of white LDS males alive was approximately 1.5 times that of white non-LDS males. The corresponding ratio for females was 1.2. The percentage alive at each age was highest among LDS females and lowest among non-LDS males. Consistent with the life expectancy analysis, the percentage of life remaining increased after adjustment was made for tobacco-related deaths.

Table 4: $\quad$ Survival (percentage alive) at selected ages from the life table for LDS and non-LDS white males and females

\begin{tabular}{lcccccc}
\hline Age $x$ & $\begin{array}{c}\text { LDS } \\
\text { Males }\end{array}$ & $\begin{array}{c}\text { Non-LDS } \\
\text { Males }\end{array}$ & Difference & $\begin{array}{c}\text { LDS } \\
\text { Females }\end{array}$ & $\begin{array}{c}\text { Non-LDS } \\
\text { Females }\end{array}$ & Difference \\
\hline Unadjusted & & & & & & \\
50 & $93.9 \%$ & $87.2 \%$ & $6.7 \%$ & $96.7 \%$ & $93.5 \%$ & $3.2 \%$ \\
60 & $88.9 \%$ & $78.9 \%$ & $10.0 \%$ & $93.5 \%$ & $88.1 \%$ & $5.4 \%$ \\
70 & $77.5 \%$ & $61.6 \%$ & $15.9 \%$ & $85.0 \%$ & $76.3 \%$ & $8.7 \%$ \\
80 & $52.5 \%$ & $34.1 \%$ & $18.4 \%$ & $65.5 \%$ & $53.1 \%$ & $12.4 \%$ \\
\hline \multicolumn{2}{l}{ Adjusted (less tobacco deaths) } & & & & \\
50 & $94.1 \%$ & $87.8 \%$ & $6.3 \%$ & $96.8 \%$ & $94.0 \%$ & $2.8 \%$ \\
60 & $89.6 \%$ & $81.3 \%$ & $8.3 \%$ & $93.7 \%$ & $89.4 \%$ & $4.3 \%$ \\
70 & $79.1 \%$ & $67.1 \%$ & $12.0 \%$ & $85.7 \%$ & $79.6 \%$ & $6.1 \%$ \\
80 & $55.3 \%$ & $42.2 \%$ & $13.1 \%$ & $66.7 \%$ & $59.0 \%$ & $7.7 \%$ \\
\hline
\end{tabular}

\section{Discussion}

This study compared life expectancy between LDS and non-LDS white males and females in Utah. The percentage of life remaining after age $x$ or the percentage still living at age $x$ from the life table was noticeably higher among LDS compared with non-LDS. However, the difference in life expectancy explained by tobacco-related deaths was only 1.5 years for males and 1.2 years for females. This means that differences in life expectancy of 5.8 years for males and 4.6 years for females were not directly explained by deaths attributed to tobacco use. 
Tobacco-related deaths did not begin to influence the percentage of life remaining until about age 60 for LDS males and females and 45 for non-LDS males and females. This is consistent with the presence of long latency periods associated with many tobacco-related diseases. A higher percentage of life remaining in LDS compared with non-LDS was observed beginning in the younger ages. Although tobacco did not contribute to this difference, this may be partly explained by the comparatively large number of accident-related deaths occurring earlier in life because of alcohol (National Center for Health Statistics 2002). Consistent with their comparatively low tobacco use, LDS also have relatively low alcohol consumption in Utah (Merrill and Thygerson 2001). It has been previously shown that in the age ranges 1-19 and 20-39, from 1994 through 1998, non-LDS experienced a higher proportion of motor vehicle deaths than did LDS (Hilton, Merrill, and Sturgeon 2001).

The higher life expectancy among LDS not explained by tobacco use may involve a number of factors associated with religious activity, such as better physical health, better social support, healthier lifestyle behaviors, and possibly an independent protective effect against mortality from religious activity itself (Wilkins 2003; Ross and Mirowsky 2002; Klein et al. 2002; McCullough et al. 2000; Ellison and Levin 1998).

A number of studies have assessed the association between religious attendance and mortality. In a nine-year follow-up study of 21,000 adults in the U.S., religious attendance at least once a week was associated with seven years of additional life expectancy (Hummer et al. 1999). A protective effect of religious attendance against mortality remained even after adjusting for social factors and health behaviors. In a 28year follow-up study of 5,286 in Alameda County, California, weekly church attendees were $25 \%$ less likely to die than infrequent church attendees (Strawbridge et al. 1997). This result was partly explained by weekly church attendees having better health practices, expanded social involvement, exercising more, and remaining married. In a five-year follow-up study of 1,931 elderly adults, aged 55 years or older, weekly church attendees experienced the lowest mortality, whereas non-church attendees had the highest mortality (Oman and Reed 1998). The protective effect of religious attendance against mortality remained even after adjustment for several potential confounding and intervening variables (demographics, health habits, marital status, social participation in activities, etc.). The study also showed that involvement in volunteer work, in addition to regular church attendance, contributed to even longer life expectancy. In a randomly selected sample of 4000 seniors, aged 64 years or older from North Carolina, followed for up to six years, the death hazard was $46 \%$ lower for frequent church attendees compared with infrequent church attendees (Koenig et al. 1999). As observed in other studies, frequent church attendees were physically healthier, had better social support, and displayed healthier lifestyle behaviors; yet adjustment for these factors failed to explain the lower mortality experienced among regular church attendees, with frequent 
attendees now 28\% (17\% for males and 35\% for females) less likely to have died during the six year follow-up period. Finally, a meta-analysis summarizing data from 42 independent samples identified a robust association between religious involvement and lower mortality (McCullough et al. 2000).

LDS Church doctrine promotes longer life among its members by discouraging use of tobacco, alcohol, coffee, and tea and recommending a nutritious diet (Doctrine and Covenants 1986a); encouraging marriage and family whenever possible (Duke 1992; Grassli 1992); encouraging education (Doctrine and Covenants 1986b); and encouraging religious activity (Doctrine and Covenants 1986c). Studies have shown that LDS are less likely than their non-LDS counterparts to smoke cigarettes, drink alcohol, coffee, or tea, and are more likely to be married, have fewer sexual partners, have more pregnancies, are slightly older at first pregnancy, are less likely to use birth control pills, and have fewer miscarriages and hysterectomies, have more years of schooling, and are more likely religiously active (Merrill, Lyon, and Jensen 2003, Merrill and Thygerson 2001, West, Lyon, and Gardner 1980).

Of the $70 \%$ of the state's population who is LDS in Utah, approximately $71 \%$ attend church weekly, compared with 33\% among other religions (Merrill and Thygerson 2001). It may be that much of the difference in the life expectancy between LDS and non-LDS could be explained by differences in the level of church attendance. Unfortunately, data were not available to perform the analyses separately by frequency of church attendance. A previous report showed for a few selected variables that differences between LDS and non-LDS adults in Utah were much less pronounced after stratifying by church activity level (Merrill and Thygerson 2001). For example, the percentage with more than a high school education was $37.5 \%$ for LDS and $36.5 \%$ for non-LDS who attended church weekly compared with $19.8 \%$ for LDS and $32.5 \%$ for non-LDS who did not attend church weekly; the percentage who were married was $76.2 \%$ for LDS and $73.6 \%$ for non-LDS who attended church weekly compared with $62.6 \%$ for LDS and $59.4 \%$ for non-LDS who did not attend church weekly; and the percentage who currently smoked was $0.4 \%$ for LDS and $8.3 \%$ for non-LDS who attended church weekly compared with $21.4 \%$ for LDS and $28.1 \%$ for non-LDS who did not attend church weekly.

Although we did not address disability adjusted life years (DALYs), tobacco use has been positively associated with considerable DALYs (Murray and Lopez 1997b). Disabilities associated with tobacco carry with them a large health-care burden (Morbidity and Mortality Weekly Report 2002, National Institute on Drug Abuse 1998). Thus, beyond the increased public health burden resulting from excess occurrence of death, this behavior results in a substantial health-care burden from disability. The fact that the LDS population displays relatively low levels of tobacco use in the U.S. may support the feasibility of the goals and objects for modifying this 
behavior in the U.S. population, set forth by Healthy People 2010 (U.S. Division of Health and Human Services 2000).

With non-LDS in Utah displaying similar prevalence of tobacco use as in the general U.S. population, the results may be relevant to the U.S. population. Other religions that strongly discourage tobacco use and alcohol-drinking (e.g., Seventh Day Adventists and Amish) may also get a sense of the potential impact this has on their average life expectancy. Given that tobacco use only explains a portion of the difference in life expectancy observed among LDS and non-LDS, understanding the other factors that explain the higher life expectancy in LDS and how these factors relate to other religions would be useful.

\section{Conclusion}

LDS males and females experience higher life and age-conditional life expectancy compared with non-LDS in Utah. Only some of the higher life expectancy in LDS is explained by historically lower use of tobacco among LDS. Tobacco-related deaths had a larger impact on the difference in life expectancy when conditioned on older ages because of the long latency period often involved with these tobacco-related diseases. Other explanations for the higher life expectancy in LDS may be related to their comparatively high level of church activity, with religiously active people often displaying better physical health, better social support, and healthier lifestyle behaviors, each of which promote longer life. Religious activity may also have an independent protective effect against mortality. 


\section{References}

Alexander TG. (1981). "The Word of Wisdom: From Principle to Requirement." Dialogue, 14, 3: 78-88.

Doctrine and Covenants of the Church of Jesus Christ of Latter-day Saints, Section 89. (1986a). Salt Lake City, Utah: The Church of Jesus Christ of Latter-day Saints.

Doctrine and Covenants of the Church of Jesus Christ of Latter-day Saints, Section 93:36. (1986b). Salt Lake City, Utah: The Church of Jesus Christ of Latter-day Saints.

Doctrine and Covenants of the Church of Jesus Christ of Latter-day Saints, Section 20:55. (1986c). Salt Lake City, Utah: The Church of Jesus Christ of Latter-day Saints.

Duke JT. "Eternal marriage." (1992). In Daniel H. Ludlow, (Ed.) Encyclopedia of Mormonism Vol. 2. New York, NY: Macmillan: 557-9.

Ellison CG, Levin JS. (1998). "The religion-health connection: Evidence, theory, and future directions." Health Educ Behav, 1998, 25, 6: 700-20.

Enstrom JE. (1975). "Cancer mortality among Mormons." Cancer, 36, 3: 825-41.

Enstrom JE. (1978). "Cancer and total mortality among active Mormons." Cancer, 42, 4: 1943-51.

Grassli MP. "Roles of children." (1992). In Daniel H. Ludlow, (Ed.) Encyclopedia of Mormonism, Vol. 1. New York, NY: Macmillan: 266-8.

Hilton S, Merrill RM, Sturgeon J. (2001). "Comparison of causes of death between LDS and non-LDS in Utah." Utah's Health: An Annual Review 7, 39-49.

Hummer RA, Rogers RG, Nam CB, Ellison CG. (1999). "Religious involvement and U.S. adult mortality.” Demography, 36, 2: 273-85.

International Classification of Diseases, $9^{\text {th }}$ Revision (Clinical Modification). 3rd ed. Washington, DC: US Department of Health and Human Services, 1989; Publ No.: [PHS] 89-1260-1.

Klein T, Lowel H, Schneider S, Zimmermann M. (2002). "Social relationships, stress and mortality." Z Gerontol Geriatr, 35, 5: 441-9.

Koenig HG, Hays JC, Larson DB, George LK, Cohen HJ, McCullough ME, Meador KG, Blazer DG. (1999). "Does religious attendance prolong survival? A six-year 
follow-up study of 3,968 older adults." J Gerontol A Biol Sci Med Sci, 54, 7: M370-6.

Kosmin BA, Lachman SP. (1993). "One nation under God: Religion in contemporary American society." New York: Harmony Books.

McCullough ME, Hoyt WT, Larson DB, Koenig HG, Thoresen C. (2000). "Religious involvement and mortality: A meta-analytic review." Health Psychol, 19, 3: 21122 .

Merrill RM, Lindsay, GB, Lyon, JL. (1999). "Tobacco-related cancers in Utah compared to the United States: Quantifying the benefits of the Word of Wisdom.” BYU Studies, 38, 91-114.

Merrill RM, Thygerson AL. (2001). "Religious preference, church activity, and physical exercise." Prev Med, 33, 1: 38-45.

Merrill RM. (2002). “Tobacco smoking and cancer in Utah.” Dialogue, 35, 4: 73-7.

Merrill RM, Hilton SC, Daniels M. (2003). "Impact of the LDS Church's health doctrine on deaths from diseases and conditions attributed to cigarette smoking." Ann Epidemiol, 13 (In press).

Merrill RM, Lyon JL, Jensen WJ. (2003). "Lack of a secularizing influence of education on religious activity and parity among Mormons." J Sci Study Relig, 42, 1: 113-24.

Michaud CM, Murray CJL, Bloom BR. (2001). "Burden of disease - implications for future research." JAMA, 285, 5: 535-9.

Morbidity and Mortality Weekly Report. (2002). "Annual smoking-attributable mortality, years of potential life lost, and economic costs - United States, 19951999. MMWR Morb Mortal Wkly Rep, 51, 14:300-3.

Morbidity and Mortality Weekly Report. (2003). "Trends in aging - United States and worldwide." MMWR Morb Mortal Wkly Rep, 52, 6:101-4, 106.

Murray CJ, Lopez AD. (1997a). "Alternative projections of mortality and disability by cause 1990-2020: Global burden of disease study." Lancet, 349, 9064, 1498-504.

Murray CJ, Lopez AD. (1997b). "Global mortality, disability, and the contribution of risk factors: Global burden of disease study." Lancet, 349, 9063, 1436-42.

National Center for Health Statistics. Health, United States, 2002 With Chartbook on Trends in the Health of Americans. Hyattsville, Maryland: 2002. 
National Institute on Drug Abuse. (1998). "Economic costs of alcohol and drug abuse estimated at $\$ 246$ billion in the United States." [NIDA web site] Retrieved May 31, 2003, from http://www.drugabuse.gov/medadv/98/MA-513.html.

Nationwide Tobacco Use, Chronic Disease Behavioral Risk Factor Surveillance System. [Centers for Disease Control and Prevention Web site] Retrieved April 16, 2003, from http://apps.nccd.cdc.gov/brfss/display.asp?cat=TU\&yr= 2000\&qkey $=621 \&$ state $=$ US.

Oman D, Kurata JH, Strawbridge WJ, Cohen RD. (2002). "Religious attendance and cause of death over 31 years. Int J Psychiatry Med, 32, 1: 69-89.

Peto R, Lopez AD, Boreham J, Thun M, Heath C Jr, Doll R. (1996). "Mortality from smoking worldwide." Br Med Bull, 52, 1: 12-21.

Ross CE, Mirowsky J. (2002). "Family relationships, social support and subjective life expectancy." J Health Soc Behav, 43, 4: 469-89.

Selvin S. (1996). Statistical analysis of epidemiologic data. 2nd ed. New York, NY: Oxford University Press; pp. 311-47.

Sen AK. (1987). The Standard of Living. Cambridge, Mass: Cambridge University Press.

Single E, Rehm J, Robson L, Truong MV. (2000). "The relative risks and etiologic fractions of different causes of death and disease attributable to alcohol, tobacco, and illicit drug use in Canada." CMAJ, 162, 12: 1669-75.

Single E, Robson L, Rehm J, Xie X, Xi X. (1999). "Morbidity and mortality attributable to alcohol, tobacco, and illicit drug use in Canada." Am J Public Health, 89, 3:385-90.

Stinson FS, Nephew TM, Dufour MC, Grant BF. (1996). State Trends in AlcoholRelated Mortality, 1979-92. U.S. Alcohol Epidemiologic Data Reference Manual, Volume 5, First Edition. Bethesda, MD: NIAAA.

Strawbridge WJ, Cohen RD, Shema SJ, Kaplan GA. (1997). "Frequent attendance at religious services and mortality over 28 years." Am J Public Health, 87, 6, 957-61.

U.S. Census Bureau. (2000a). 2000 Statistical Abstract of the United States. No. 76. Christian Church Adherents, 1990, and Jewish Population, 1998 - State. [United States Bureau of the Census Web site] Retrieved April 30, 2003, from http://landview.census.gov/prod/2001pubs/statab/sec01.pdf. 
U.S. Census Bureau. (2000b). Methodology for estimating state and county total population. [United States Bureau of the Census Web site] Retrieved May 15, 2003, from http://www.census.gov/population/methods/stco99.txt.

U.S. Census Bureau. (2001). Utah 2001 population estimates. [United States Bureau of the Census Web site] Retrieved April 30, 2003, from http://quickfacts. census.gov/qfd/states/49000.html.

U.S. Department of Health and Human Services. Reducing the health consequences of smoking: 25 years of progress, A Report of the Surgeon General. Chapter 3. Rockville, Md: U.S. Department of Health and Human Services, Public Health Service, Centers for Disease Control, National Center for Chronic Disease Prevention and Health Promotion, Office of Smoking and Health; 1989.

U.S. Department of Health and Human Services. Healthy People 2010, Volume II. (2000). U.S. Department of Health and Human Services, United States Government Printing Office.

Utah Health Status Survey Codebook, 2nd ed. (1996). Bureau of Surveillance and Analysis, Office of Public Health Data, Utah Department of Health.

Wajda A, Roos LL, Layefsky M, Singleton JA. (1991). "Record linkage strategies: Part II. Portable software and deterministic matching." Methods Inf Med, 1991, 30:210-14.

Washington, DC: U.S. Government Printing Office, November 2000. Retrieved May 29, 2003, from http://www.healthypeople.gov/Document/ HTML/Volume2/toc.htm

West DW, Lyon JL, Gardner JW. (1980). "Cancer risk factors: an analysis of Utah Mormons and non-Mormons." J Natl Cancer Inst, 65, 5:1083-95.

Wilkins K. (2003). "Social support and mortality in seniors." Health Rep 14, 3: 21-34. 